\title{
Microstrip Antenna Design by Entrenching the Ground Plane Around the Patch
}

\author{
Dhanasekaran Sundararaj, Padmanabhan K, Ananthi Sabapathy
}

\begin{abstract}
A new approach to enhance the Front-To-Back Ratio (FTBR) of aninset fed microstrip patch antennabyentrenching the ground plane encircling the patch is described in this paper.By entrenching the groundplane around patch,backlobe of the antenna getssuppressed.The FTBRhas been improvedto a value of $48.25 \mathrm{dBi}$, which is very much higher compared to the FTBR of reference microstrip antenna 13.29 dBi.
\end{abstract}

Index terms-Microstrip Antenna,Backlobe Suppression, FrontTo-Back Ratio.

\section{INTRODUCTION}

The rectangular microstrip antennas is probably the most popular microstrip antenna design implemented by the designers[1].The main advantages of the microstrip antennas arelow cost fabrication,can be made on the surface of the product,low thickness, low profile, light weight ,supports multiband operation[1-2].However, it has thedrawbacks of narrow bandwidth,low gain,poor cross polarization and undesirable backlobes.

The back lobe radiation is undesirable because a portion of energy is transmitted in an undesired direction.This energytransmitted in undesired direction may lead to interference with other wireless systems if the frequency is reused[3].

FTBR is avitalfactorto be observed when the transmitted signal is not intended on the backside of the antenna.Back lobe canbe suppressed by sacrificing some level of the gain in the forwarddirection [4].

Surface waves mainly contribute to the formation of back lobe.The ground plane guides the excited surface waves towards the edge of antenna. When the surface waves reach the edge of the ground plane they get diffracted [7],[9]. Surface waves have a zero cut off frequencyand hence they are always excited [7].Our interest isto design a microstrip patch antenna with reduced back radiation by suppressing the propagation of surface waves.

In [3], a slot antenna was designed with parasitic patches on the opposite side and also along the slot axis to reduce back lobe.In [5] a comb shapedchoke has been used to effectively suppress the diffraction of surface wave and therefore to reduce the back lobe. Inanother paper[6],ground plane edges were shapedto achieve an increased Front-toback ratio in a microstrip patch antenna.

Revised Version Manuscript Received on Jun 20, 2019.

S.Dhanasekaran, Pursuing Ph.D in the Department of Network Systems \& Information Technology, University of Madras.

K.Padmanabhan, A.I.C.T.E. Emeritus Professor, Anna University.

S. Ananthi, Professor, ECE in MVJCE.

\section{ANTENNA DESIGN}

The structure of the proposed inset-fed microstrip antenna is shownin Fig.1.The dimensions of the antenna (width $\mathrm{x}$ length) are $56.8 \mathrm{~mm} \mathrm{x} 47.4 \mathrm{~mm}$ (2692.32 $\mathrm{mm}^{2}$ ). The microstrip patch antenna designed for $2.45 \mathrm{GHz}$ antenna is inset fed which is fed by a $50 \Omega$ transmission line .The width of transmission line is $3.0 \mathrm{~mm}$ with a feed line gap of $2.59 \mathrm{~mm}$ on either side of the microstrip feed line. An FR-4 substrate with a relative permittivity of 4.3 and a thickness of $1.6 \mathrm{~mm}$ is used.

A trench is madeon the ground plane encircling the patch except a strip of conductor unetched with a width of 0.5 along the mid of E-plane( shown as $\mathrm{Sg}$ ) asin Fig.2.The effect of trench in the ground plane beneath the patch was investigated. The back lobe gets reduced considerably. Analysis was carried outby using CST Microwave Studio 2016.The location and width of the trench was optimized for maximum cancellation of back lobe.

TABLE I.

Antenna Dimensions

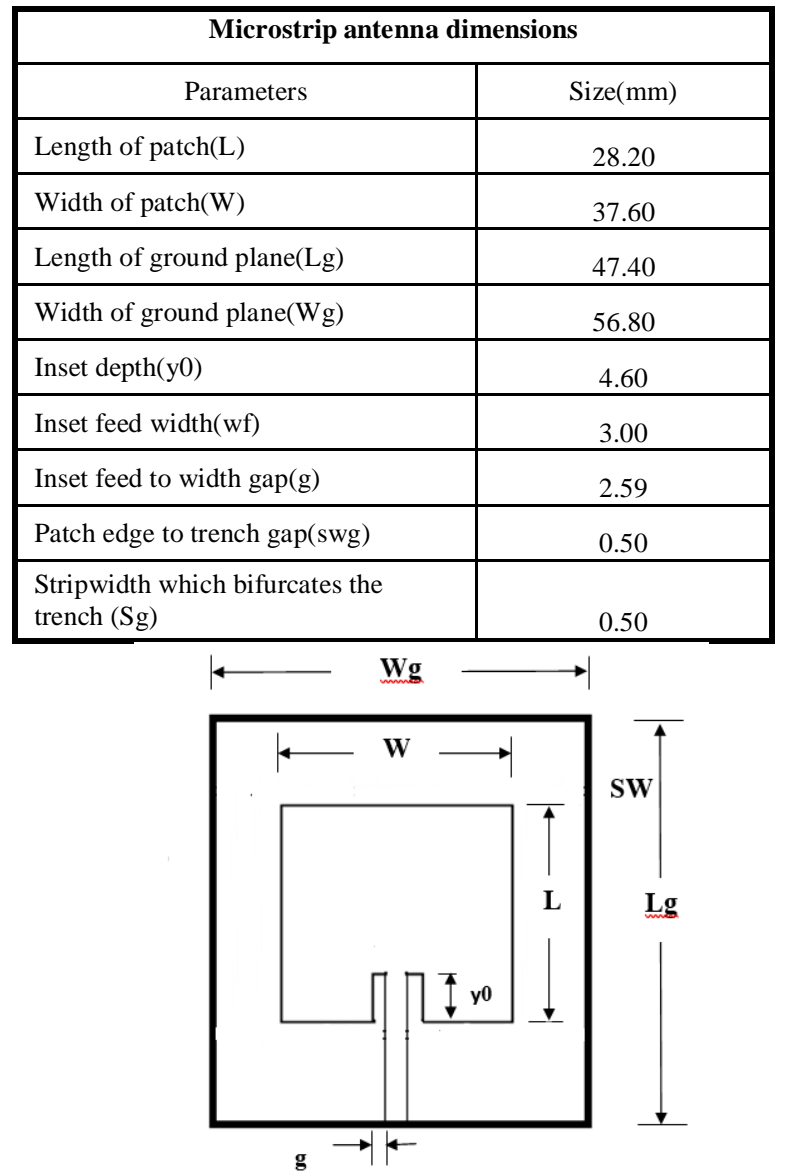

Fig.1 Geometry of the reference Microstrip patch antenna 


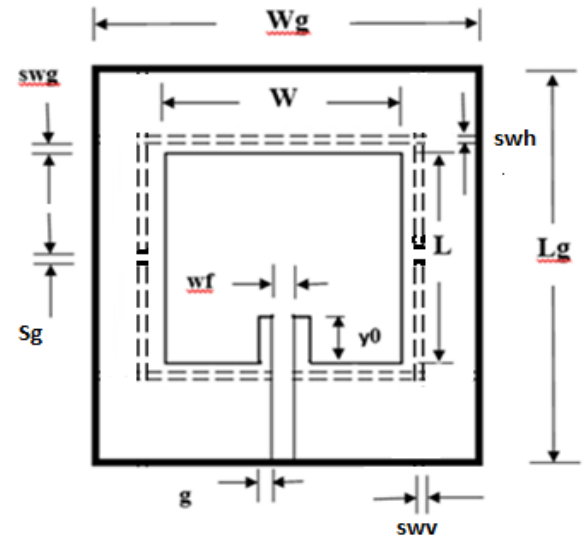

Fig.2. Geometry of Microstrip patch antenna by entrenching the ground planearound the patch (Top view)

\section{ANALYSIS,RESULTS AND DISCUSSION}

The presence of ground plane trencharound the patch suppresses the surface wave propagation thereby reduces the formation of back lobe.

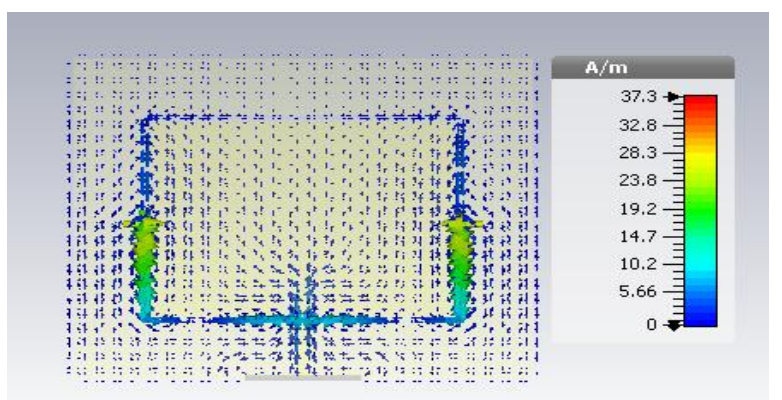

Fig.3 Surface current in the groundplane of proposed microstrip antenna

From Table 2, itis observed that the peak Front-to-Back ratio hasimproved from $13.29 \mathrm{dBi}$ to $48.25 \mathrm{dBi}$ (Fig.7).The broadside lobe gain has reduced from $3.04 \mathrm{dBi}$ to $2.05 \mathrm{dBi}$.

Won-Gyu Lim in [10] has described that high impedance at the microstrip ground plane edge reduces theformation of back lobe. From Fig. $3 \& 4$ it can be observed that stronger surface currents are concentrated at the centre of the trenches in E- plane. It is found that high impedance is observed at the trenches in horizontal plane. It can also be inferred from Fig .4 that the surface current on the either side of the trenches of ground plane are oppositely directed leading to transmission line mode. In this mode the $\mathrm{E}$ and $\mathrm{H}$ fields in the direction normal to the ground plane gets cancelled out due to thecurrent with equal amplitude flowing in the opposite direction.

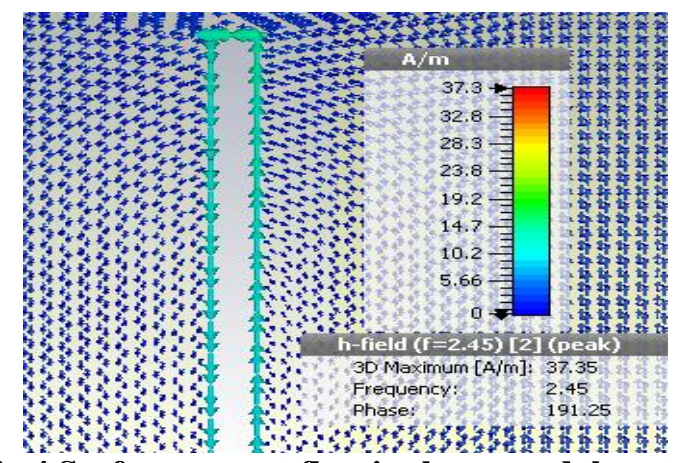

Fig.4 Surface current flow in the groundplane trench

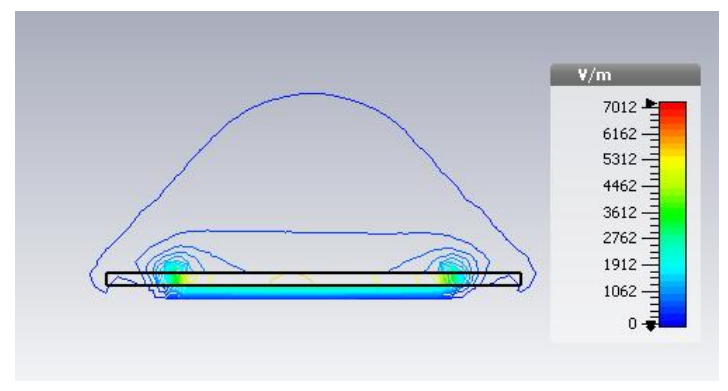

Fig.5 Electric field edge diffraction in the H-plane of thereference antenna (Side view)

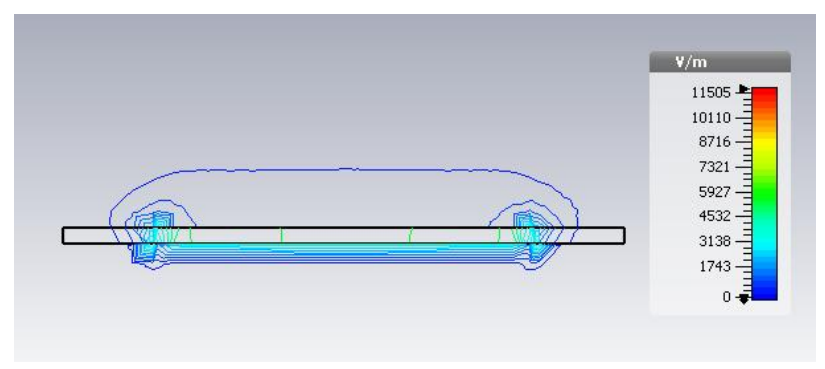

Fig.6 Electric field edge diffraction in theH-plane of the Patch antenna with trench in the ground plane (Side view)

From Fig 6, it can be inferred that high impedance formed at the edges of ground plane due to entrenching of ground plane has led to high attenuation of surface waves and therefore less edge diffraction and back lobe, whereas the edge diffraction in the reference antenna is more as shown in Fig 5.Reduction of the gain in the broadside direction indicates thatthe surface waves have also reducedthe forward by increasing the radiating angle.

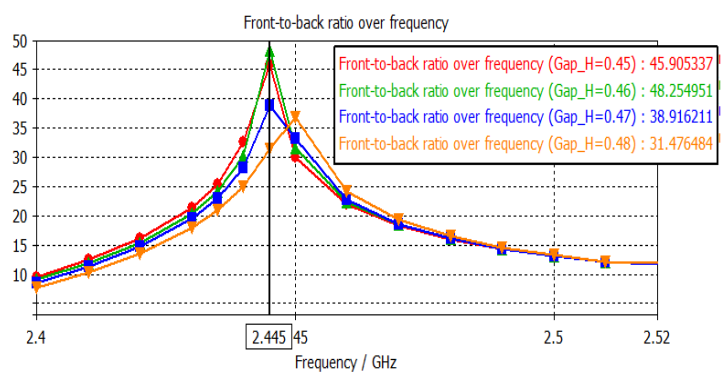

Fig.7. FTBR of proposed Antenna Design 
TABLE II.

FTBR analysis of microstrip antenna by changing the H-Plane trench width

\begin{tabular}{|c|c|c|c|c|c|c|c|}
\hline Antenna & $\begin{array}{c}\text { Width of } \\
\text { trench } \\
\text { inH-Plane } \\
(\mathbf{m m})\end{array}$ & $\begin{array}{l}\text { Width of } \\
\text { trench inE- } \\
\text { Plane } \\
(\mathbf{m m})\end{array}$ & $\begin{array}{c}\text { Width of the } \\
\text { unetched } \\
\text { strip(sg) } \\
(\mathbf{m m})\end{array}$ & $\begin{array}{c}\text { Resonant } \\
\text { Frequency } \\
\text { (GHz) }\end{array}$ & $\begin{array}{l}\text { Reflection co- } \\
\text { efficient }\end{array}$ & $\begin{array}{c}\text { Forward } \\
\text { Gain } \\
(\mathbf{d B i})\end{array}$ \\
\hline Reference & - & - & - & 2.42 & -25.02 & 3.04 & $\begin{array}{c}\text { Peak } \\
\text { FTBR } \\
(\mathbf{d B i})\end{array}$ \\
\hline Design 1 & 0.45 & 0.41 & 0.5 & 2.47 & -21.18 & 2.07 \\
\hline Design 2 & 0.46 & 0.41 & 0.5 & 2.47 & -21.12 & 2.05 \\
\hline Design 3 & 0.47 & 0.41 & 0.5 & 2.47 & -20.87 & 2.04 \\
\hline Design 4 & 0.48 & 0.41 & 0.5 & 2.47 & -20.78 & 38.91 \\
\hline
\end{tabular}

\section{CONCLUSION}

In this paper a new configuration by entrenching the ground plane around the patch isproposed to suppress the radiation on the backside of inset fed microstrip antenna.It is shown that backlobe level of the microstripantenna can be reduced by $34.71 \mathrm{dBi}$ by sacrificing a gain of $1 \mathrm{dBi}$ in the broadsidedirection. The proposed microstrip antenna is unidirectional and can be fabricated with ease.By thisapproach back lobe of microstrip antenna can bereducedwithout increasing the ground planedimension and without adding reflectors. This technique can also be used for increasing isolationbetween closely-spaced MIMO antennas.

\section{REFERENCES}

1. Randy Bancroft, "Microstrip and Printed Antenna Design", Scitech Publishing, Inc,Raleigh ,NC.2009,pp.10-75.

2. C.A.Balanis, "Antenna Theory : Analysis and Design", Wiley India P Ltd, 2005.pp 811-882.

3. Qinjiang Rao, T.A.Denidhi,R.H.Johnston, "A new aperture coupled microstrip slot antenna", IEEE Transactions on Antennas and Propagation, Vol 53,No.9,Sep 2005.

4. Zhi Ning Chen,Qing Xianming,Jin Shi, "Compact Substrate Integrated Waveguide Slot Antenna Array With Low Back Lobe",IEEE Antennas and Wireless Propagation letters ,Vol 12,2013

5. Jie Wei,Shaoweri Liao,Jianhua Xu ,Zhi Ning Chen,Xianming Qing,Jin Shi, "SIW slot antenna array with low back lobe",IEE Asia-Pacific Conference on Antennas and Propagation,Aug 2013.

6. T.J.Cho,H.M. Lee, "Front-to-Back ratio improvement of a microstrip antenna by ground plane edge shaping", IEEE 2010

7. Hong-Min Lee, "Front-to-Back ratio improvement of a Microstrip Patch Antenna Loaded with Surface Structure in a Partial Removed Grond Plane", Journal of Electromagnetic Engineering and Science, Vol.12,No.4,247-253,Dec 2012.

8. Rafael A.Rodriguez Solis, Ana Medina,Nestor Lopez, "Microstrip Patch Encircled by Trench",IEEE 2000.

9. Siew Bee Yeap,Zhi Ning Chen, "Microstrip Patch Antennas with Enhanced gain by Partial substrate removal",IEEE Transactions on Antennas and Propagation, Vol 58,No.9, Sep 2010.

10. Won-Gyu Lim, "New method for backlobe suppression of microstip patch antenna for GPS'.Proceedings of $40^{\text {th }}$ European Microwave Conference,28-30September2010,Paris,France

\section{Authors Profile}

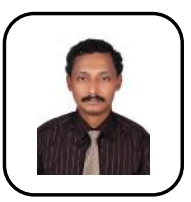

S.Dhanasekaran received his B.E., in Electronics and Communication Engg and M.E.,in Applied Electronics in the year 2001 and 2003 respectively from BharathiarUniversity,Coimbatore.Since 2003 he is working as an Engineer in BSNL,Chennai Telephones.He is currently pursuing $\mathrm{Ph} . \mathrm{D}$ in the Department of Network Systems \& Information Technology, University of Madras,Guindy campus under the guidance of Dr.S.Ananthi in the field of Microstrip Antennas.

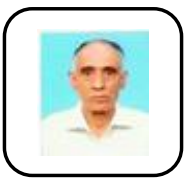

Dr.K.Padmanabhan, did his Grad.Brit.IRE, B.E from Guindy Engineering College and Doctorate from the Madras University and has served a Professor and Head of the Instrumentation Centre, University of Madras. After retirement, he is A.I.C.T.E. Emeritus Professor in the Anna University. $\mathrm{He}$ is a Fellow of IETE,IEE and Sr. Member IEEE. His areas of specialization range from Applied Electronics, Microprocessors, Telecommunications and DSP.

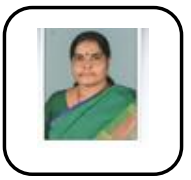

Dr.S.Ananthi got her B.E. in ECE from the Anna University. She did M.Tech. at the Indian Institute of Scienceand later did Doctorate from University of Madras. She worked in the University as Professor and Headi/cof NSIT department till June 2018.After retirement, she is Professor, ECE in MVJCE. Her areas of specialization includes in DSP, Adv. Communication and Biomedical telemetry. She was awarded the Env. TN award for the year2004. 